ISSN = 1980-993X - doi:10.4136/1980-993X
www.ambi-agua.net
E-mail: ambi-agua@agro.unitau.br
Tel.: (12) 3625-4212

\title{
Bacterias resistentes a antibióticos en aguas grises como agentes de riesgo sanitario
}

\author{
(http://dx.doi.org/10.4136/ambi-agua.638)
}

\author{
Lidia Nuñez ${ }^{1}$; Carina Tornello ${ }^{2}$; Noel Puentes ${ }^{3}$; Juan Moretton ${ }^{4}$ \\ Cátedra de Higiene y Sanidad, Facultad de Farmacia y Bioquímica, \\ Universidad de Buenos Aires, Argentina \\ 'e-mail: lidian@ ffyb.uba.ar; ${ }^{2}$ carinatornello@yahoo.com.ar; \\ 3noelsonik@hotmail.com; ${ }^{4}$ jamorett@ffyb.uba.ar
}

\section{RESUMEN}

La eliminación y disposición final de las aguas residuales originadas por las actividades domésticas constituye un importante problema sanitario en áreas urbanas densamente pobladas. En muchas zonas del Gran Buenos Aires las aguas grises se eliminan en zanjas a cielo abierto cuyo riesgo potencial no ha sido adecuadamente cuantificado. El objetivo de este trabajo fue evaluar la prevalencia de bacterias resistentes y el perfil de resistencia a antibióticos, en muestras de aguas grises de canales localizados en la zona de Ingeniero Budge Provincia de Buenos Aires. Se determinó por el método de dilución en agar la prevalencia de bacterias heterotróficas, bacterias Gram-negativas resistentes a antibióticos betalactámicos y enterococos vancomicina resistentes en aguas grises. Se determinó el género y la especie y se estableció el perfil de resistencia frente a otros antibióticos. De todos los antibióticos ensayados, la mayor prevalencia de bacterias heterotróficas resistentes se detectó con la cefalotina (19\%) y ampicilina (8\%). Con respecto, a las bacterias Gram-negativas, la mayor prevalencia de resistencia está dada por los coliformes frente a ampicilina (34\%) y cefalotina (17\%). Se detectó un 38\% de enterococos con bajo nivel de resistencia a vancomicina. Los aislamientos multirresistentes se identificaron como Escherichia coli, Alcaligenes faecalis y Stenotrophomonas maltophilia. Estos resultados indican que las aguas grises pueden considerarse como un reservorio de bacterias resistentes a los antibióticos, aumentando así su riesgo sanitario

Palabras-clave: resistencia a antibióticos; agua gris; antibióticos $\beta$ lactámicos.

\section{Health risks associated with the presence of antibiotic resistant bacteria in greywater}

\begin{abstract}
The removal and disposal of waste from domestic activities is a major health problem in densely populated urban areas. In many areas of Greater Buenos Aires, greywater is disposed in open ditches and risk potential of this has not been adequately quantified. The aim of this study was to evaluate the prevalence of antibiotic-resistant bacteria and its resistance profile present in raw greywater obtained from a channel located in the area of Ingeniero Budge Buenos Aires Province. Thus, the prevalence of heterotrophic bacteria, Gram-negative bacteria resistant to beta-lactam antibiotics and vancomycin-resistant enterococci in greywater, their typing, and resistance to other antibiotics were determined. The prevalence of resistant bacteria was determined by the agar dilution method. Of all the antibiotics tested, the
\end{abstract}


NUÑEZ, L; TORNELlO, C.; PUENTES, N.; MORETTON, J. Bacterias resistentes a antibióticos en aguas grises como agentes de riesgo sanitario. Ambi-Agua, Taubaté, v. 7, n. 1, p. 235-243, 2012. (http://dx.doi.org/10.4136/ambi-agua.638)

highest prevalence of resistant heterotrophic bacteria was detected with cephalothin (19\%) and ampicillin (8\%). With regard to Gram-negative bacteria, the highest prevalence of resistance was given by coliforms ampicillin (34\%) and cephalothin (17\%). A total of 38\% of enterococci with low level resistance to vancomycin was detected. The multiresistant isolates were identified as Escherichia coli, Alcaligenes faecalis y Stenotrophomonas maltophilia. These results indicate that greywater can be considered as a reservoir of bacteria resistant to antibiotics, thus increasing their health risk.

Keywords: antibiotic- resistance; greywater; $\beta$-lactamic antibiotic.

\section{Riscos à saúde associados com a presença de bactérias resistentes a antibióticos em águas cinzas}

\section{RESUMO}

A remoção e eliminação dos resíduos resultantes da atividade doméstica é um grave problema de saúde em áreas urbanas densamente povoadas. Em muitas áreas dos subúrbios de Buenos Aires, as águas cinzas são depositadas em canais abertos, cujo risco sanitário potencial não tem sido devidamente quantificado. O objetivo deste estudo foi avaliar a prevalência de bactérias resistentes a antibióticos presentes em águas cinzas brutas obtidas de um canal localizado na área de Ingeniero Budge, Província de Buenos Aires, bem como seu perfil de resistência. Para isso, determinou-se a prevalência de bactérias heterotróficas, bactérias Gram-negativas resistentes a antibióticos beta-lactâmicos e enterococos resistentes a vancomicina em águas cinzas, a sua tipificação, e resistência a outros antibióticos. A prevalência de bactérias resistentes foi determinada pelo método de diluição em agar. De todos os antibióticos testados, a maior prevalência de resistência de bactérias heterotróficas, foi detectada com cefalotina (19\%) e ampicilina (8\%). Com relação às bactérias Gramnegativas, a maior prevalência de resistência é dada por coliformes ampicilina (34\%) e cefalotina (17\%). Foram detectados $38 \%$ dos enterococos com baixo nível de resistência à vancomicina. As bactérias multirresistentes foram identificadas como Escherichia coli, Alcaligenes faecalis y Stenotrophomonas maltophilia. Estes resultados indicam que a água cinza pode ser considerada como um reservatório de bactérias resistentes aos antibióticos, aumentando o risco microbiológico.

Palavras-chave: resistência a antibióticos; água cinza; antibióticos $\beta$ - lactámicos.

\section{INTRODUCCIÓN}

El desarrollo y diseminación de bacterias resistentes a antimicrobianos está generando una preocupación creciente ya que las bacterias resistentes producen infecciones difíciles de tratar y de controlar. La farmacoterapia para dichas infecciones es costosa y en muchos casos no disponible para un gran grupo de población. En consecuencia, estas propiedades de resistencia bacteriana se están convirtiendo en un problema sanitario, ecológico y económico (Gomez et al., 2007).

La incidencia de bacterias resistentes a antibióticos en el medio acuático se ha incrementado como consecuencia de la utilización a gran escala de los antibióticos. La resistencia a los antibióticos se ha detectado en bacterias presentes en líquidos clocales urbanos (Heuer et al., 2002; Tennstedt et al., 2003), en líquidos residuales hospitalarios (Reinthaler et al., 2003; Schwartz et al., 2003), en barros cloacales (Guillaume et al., 2000; Reinthaler et al., 2003), en aguas subterráneas (Gallert et al., 2005), en ríos contaminados con descargas cloacales (Costanzo et al., 2005). Pocos estudios se han realizado con los efluentes 
conocidos como aguas grises a pesar de ser una de las formas clásicas de eliminación de aguas residuales en las grandes zonas periurbanas de Latinoamérica.

Las aguas grises pueden definirse como los líquidos residuales domiciliarios provenientes de duchas, lavado de ropa, alimentos y vajilla. Por su origen esta agua transportan una significativa carga microbiana cuyas características dependerán de las actividades domésticas desarrolladas en la comunidad (Gross et al., 2007; Casanova et al., 2001). La carga contaminante es menor que la de los líquidos cloacales pero la detección de microorganismos de contaminación fecal indica la potencial presencia de enteropatógenos. Diferentes estudios aislaron agentes patógenos oportunistas como Pseudomonas aeruginosa y Staphylococcus aureus (Birks and Hills, 2007; Gilboa and Friedler, 2008). El agua gris también puede contener patógenos introducidos por la manipulación de los alimentos como Salmonella y bacterias resistentes a antibióticos, de origen humano o animal (Nuñez et al., 2010).

El objetivo de este trabajo fue evaluar la prevalencia de bacterias resistentes a antibióticos presentes en las aguas grises crudas obtenidas de canales localizados en la zona de Ingeniero Budge, Provincia de Buenos Aires, como así también su perfil de resistencia. Para esto se determinó la prevalencia de bacterias heterotróficas, bacterias Gram-negativas resistentes a antibióticos betalactámicos y enterococos vancomicina resistentes en aguas grises, su tipificación y perfil de resistencia frente a otros antibióticos.

La zona seleccionada presenta características de eliminación de aguas similar a otras de la Provincia sumada a una serie de dificultades que la transforman en el escenario más complejo de la región. Los canales a cielo abierto que drenan las aguas grises hacia otros canales mayores que a su vez desembocan en la cuenca Matanza Riachuelo están construidos en terrenos bajo la cota de este río, como consecuencia, el desagüe es dificultoso y durante temporadas de lluvias los canales desbordan cubriendo las zonas habitables de casas y aceras. Estos desbordes incrementan el contacto de los habitantes con las aguas grises y como consecuencia, producen un riesgo que debe ser cuantificado.

\section{MATERIAL Y MÉTODOS}

\subsection{Muestreo}

Se tomaron muestras mensuales durante un año, de mayo de 2008 a abril de 2009 en un canal en Ingeniero Budge, Provincia de Buenos Aires. Todas las muestras se recogieron en una sola toma en bidones de polietileno de 5 litros. Las muestras se conservaron refrigeradas a $4^{\circ} \mathrm{C}$, y fueron procesadas el mismo día de la toma de muestra.

\subsection{Determinación del porcentaje de bacterias resistentes}

Las bacterias son cuantificadas por el método de recuento en placa. De alícuotas de las muestras se prepararon diluciones decimales seriadas $10^{-1}$ a $10^{-4}$ en solución fisiológica y se sembraron por duplicado en placas con medios de cultivo con y sin antibióticos en superficie $(0,1 \mathrm{~mL})$ que se incubaron $24 \mathrm{~h}$ a $35^{\circ} \mathrm{C}$.

Diferentes medios selectivos se utilizaron: agar Slanetz-Bartley para enterococos, y Violeta rojo bilis lactosa agar, como medio de cultivo selectivo, para bacilos Gram negativos. Para el recuento de bacterias heterotróficas se utilizó Mueller-Hinton agar.

Para evaluar el porcentaje de bacterias resistentes se agregaron los siguientes antibióticos:

En Mueller-Hinton agar se utilizaron: $\beta$-lactamicos: ampicilina $(32 \mu \mathrm{g} / \mathrm{mL})$, ceftriaxona $(64 \mu \mathrm{g} / \mathrm{mL})$, cefalotina $(32 \mu \mathrm{g} / \mathrm{mL})$, ceftazidima $(32 \mu \mathrm{g} / \mathrm{mL})$; aminoglucósidos: gentamicina (16 $\mu \mathrm{g} / \mathrm{mL})$; quinolonas: ciprofloxacina $(4 \mu \mathrm{g} / \mathrm{mL})$, 
NUÑEZ, L; TORNELlO, C.; PUENTES, N.; MORETTON, J. Bacterias resistentes a antibióticos en aguas grises como agentes de riesgo sanitario. Ambi-Agua, Taubaté, v. 7, n. 1, p. 235-243, 2012. (http://dx.doi.org/10.4136/ambi-agua.638)

En Violeta rojo bilis lactosa agar: $\beta$-lactámicos: ampicilina, ceftriaxona, cefalotina, ceftazidima .

El agar Slanetz-Bartley se suplementó con $6 \mu \mathrm{g} / \mathrm{mL}$ de vancomicina.

La prevalencia de bacterias resistentes se ha calculado como el número de bacterias que crecen en los medios que contiene antibióticos, dividido por el número de bacterias que crecen en medios que no contienen antibióticos. Las pruebas de sensibilidad a los antibióticos se han realizado por duplicado.

Las cepas aisladas en los medios de cultivo con antibiótico se tipificaron.

Los enterococos se identificaron mediante los ensayos de catalasa, la hidrólisis de esculina y hemólisis en agar sangre. Todos los aislamientos de enterococos vancomicina resistentes son confirmados utilizando API 20 Strep (Biomerieux). Los bacilos Gram negativos se tipificaron mediante la coloración de Gram, el ensayo triple azúcar hierro (TSI), la reacción de oxidasa, la reducción de nitratos y el sistema de identificación de bacterias API 20E y API 20NE (Biomereux). A los cocos Gram positivos aislados de Mueller-Hinton agar se les realizó la prueba de catalasa. En el caso de ser catalasa positivos se efectuó el ensayo de óxido-fermentación, se sembró en caldo con $6.5 \%$ de $\mathrm{ClNa}$, y se confirmó con el sistema API Sth.

\subsection{Ensayos de susceptibilidad antimicrobiana}

Para determinar el perfil de resistencia de los bacilos Gram negativos aislados de los medios de cultivo con antibióticos se utilizó la técnica de difusión en agar Mueller- Hinton. Se utilizaron discos con los siguientes antibióticos: imipenen, meropenen, gentamicina, amicacina, ciprofloxacina, trimetoprima-sulfametoxazol, ampicilina-sulbactan, cefalotina, cefepime, ceftazidima, cefotaxima, piperacilina-tazobactan.

A los enterococos vancomicina resistentes se les determinó la concentración inhibitoria mínima (CIM) por el método de dilución en agar. Se realizó frente a los siguientes antibióticos: vancomicina (V), ampicilina (AMP), gentamicina (GM), tetraciclina.

Cuando se aislaron cocos Gram positivos de los medios de cultivo con antibiótico, se determinó la resistencia a cefoxitina, oxacilina, vancomicina, eritromicina, teicoplamina, clindamicina mediante el método de difusión.

Las pruebas de sensibilidad se han realizado siguiendo las normas del Clinical and Laboratory Standards Institute (CLSI, 2008).

\section{RESULTADOS}

En la Tabla 1 se observan la concentración de las bacterias detectadas en las muestras de agua gris.

Tabla 1. Concentración bacteriana en las muestras de agua gris.

\begin{tabular}{l|c|c|c|c}
\hline & Bacterias heterotróficas & Coliformes & Bacilos & Enterococos \\
\hline Média & $9.8 \times 10^{5}$ & $4.1 \times 10^{5}$ & $3.4 \times 10^{5}$ & $3.2 \times 10^{3}$ \\
Mínimo & $3.3 \times 10^{5}$ & $2.0 \times 10^{4}$ & $4.0 \times 10^{4}$ & $1.4 \times 10^{3}$ \\
Máximo & $9.8 \times 10^{6}$ & $4.5 \times 10^{6}$ & $2.5 \times 10^{6}$ & $2.0 \times 10^{4}$ \\
\hline
\end{tabular}


NUÑEZ, L; TORNELlO, C.; PUENTES, N.; MORETTON, J. Bacterias resistentes a antibióticos en aguas grises como agentes de riesgo sanitario. Ambi-Agua, Taubaté, v. 7, n. 1, p. 235-243, 2012. (http://dx.doi.org/10.4136/ambi-agua.638)

\subsection{Bacterias heterotróficas}

Se han aislado bacterias heterotróficas resistentes a los antibióticos ensayados en todas las muestras. La Figural muestra el porcentaje de bacterias heterotróficas resistentes a los antibióticos. De todos los antibióticos ensayados, la mayor prevalencia de resistencia se detectó con la cefalotina (19\%) y ampicilina (8\%) con valores máximos de 52 y $30 \%$ y con valores mínimos de 0,2 y 0,5\%, respectivamente Entre los antibióticos no betalactámicos, se observó una mayor resistencia a tetraciclina $(1,4 \%)$.

Los aislamientos resistentes fueron predominantemente bacilos Gram-negativos no fermentadores como la Stenotrophomonas maltophilia, Acinetobacter spp, Alcaligenes faecalis. y Psychrobacter phenylpyruvicus. En los perfiles de resistencia observamos que la resistencia a algunos antibióticos es natural como la resistencia de $S$ maltophilia a meropenen y Alcaligenes faecalis a gentamicina. (Tabla 2).

También se aislaron cocos Gram+ resistente a ampicilina y a cefalotina.Estos se identificaron como estafilococos coagulasa negativa. Todos los aislamientos fueron resistentes a cefoxitina y se observó resistencia a vancomicina en el $50 \%$ de dichos aislamientos. Además entre los cocos Gram+ se han aislado cepas identificadas principalmente como Alloiococcus spp y Gemella spp resistentes a cefalosporinas (cefoxitina, ceftazidima y oxacilina).

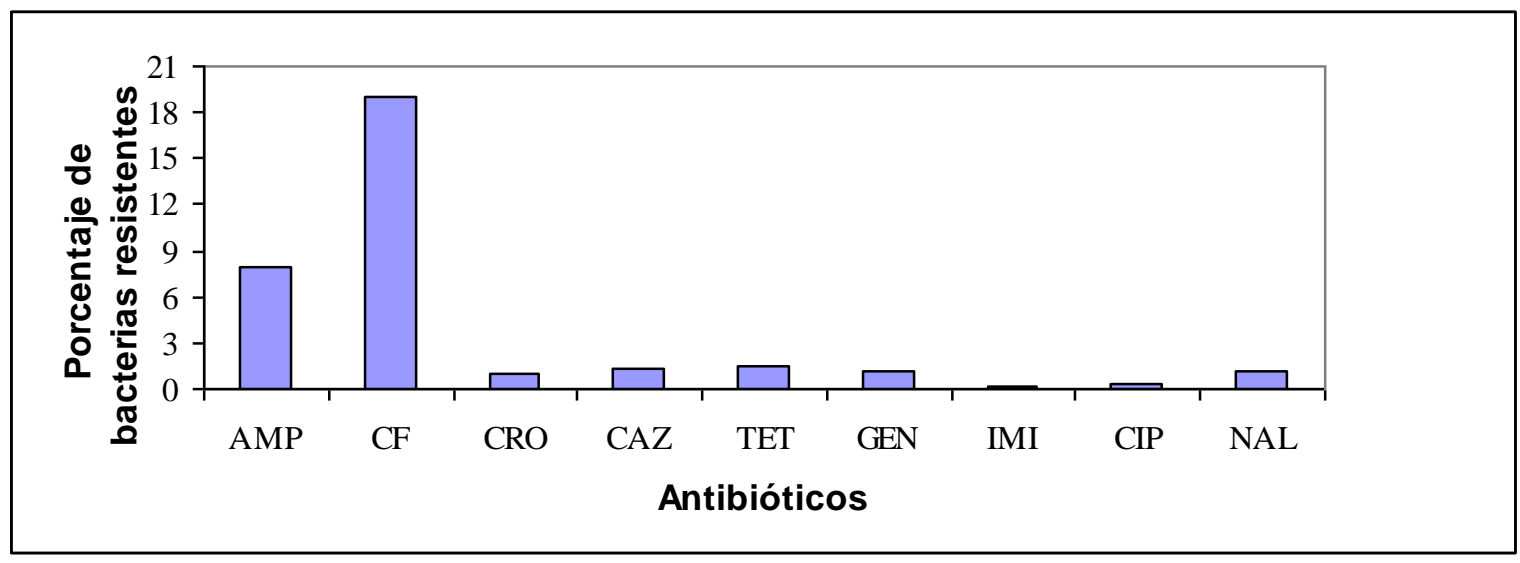

Figura 1. Prevalencia de bacterias heterotróficas resistentes a antibióticos.

\subsection{Bacterias Gram-negativas}

En todas las muestras se detectaron coliformes resistentes a cefalotina y ceftazidima, y con respecto a ampicilina y ceftriaxona, se observaron la presencia de coliformes resistentes en el $90 \%$ de las muestras. Se detectó bacilos Gram negativos no fermentadores de lactosa resistentes a ceftazidima en todas las muestras ensayadas. En cambio, frente a los demás antibióticos se observó resistencia en 80.0 a $90.0 \%$ de las muestras ensayadas.

Se observó una mayor resistencia a ampicilina con un $34.0 \%$ de bacterias coliformes resistentes, seguida por las bacterias resistentes a cefalotina (17.0\%) y alcanzando valores máximos de $100.0 \%$ y $37.0 \%$ y mínimos de 0.1 y $1.1 \%$ respectivamente. Con respecto a los bacilos Gram negativos no coliformes, también se detectó una mayor resistencia a ampicilina, seguida por la cefalotina (valores medios de 20.0 y $12.0 \%$ ) y alcanzando valores máximos de $87.0 \%$ y $40.0 \%$ y mínimos de 3.0 y $2.0 \%$ respectivamente (Figura 2 ).

Los aislamientos de coliformes resistentes fueron identificados como Escherichia coli, los cuales presentaron multirresistencia (Tabla 2).

Con respecto a los aislamientos no fermentadores de lactosa, todos fueron resistentes a cefalotina, ampicilina, ampicilina-sulbactan y a trimetoprima-sulfametoxazol. El 10\% de estos aislamientos fue también resistente a meropenen. 
NUÑEZ, L; TORNELlO, C.; PUENTES, N.; MORETTON, J. Bacterias resistentes a antibióticos en aguas grises como agentes de riesgo sanitario. Ambi-Agua, Taubaté, v. 7, n. 1, p. 235-243, 2012. (http://dx.doi.org/10.4136/ambi-agua.638)

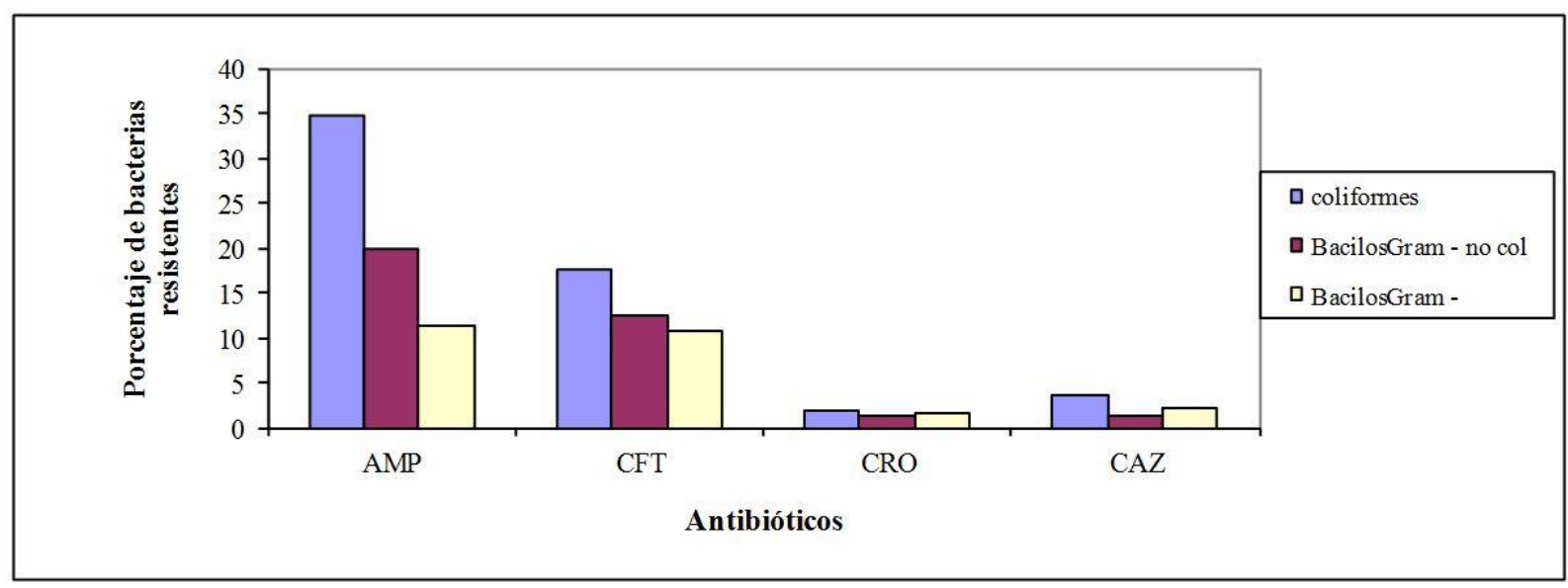

Figura 2. Prevalencia de bacilos Gram negativos resistente a antibióticos $\beta$ - lactámicos.

Tabla 2. Perfil de resistencia de los principales aislamientos.

\begin{tabular}{c|c}
\hline MICROORGANISMOS & PERFIL DE RESISTENCIA \\
\hline Stenotrophomonas maltophilia & MEN-CF-TMS-AMS-FEP \\
Acinetobacter spp & MEN-CIP-CF-AKN-AMS \\
Acinetobacter spp & MEN-CF-CTX-TMS-CAZ-AMS \\
Alcaligenes faecalis & CIP-FEP-TMS-GEN-CAZ \\
Psychrobacter phenylpyruvicus & MEN-TAZ-FEP-CF-CTX-TMS-GEN-CAZ-AMS \\
Escherichia coli & MEN-TAZ-FEP-CF-CAZ-AMS-CTX \\
\hline
\end{tabular}

\subsection{Enterococos resistentes}

Se obsevaron valores medios de $58.6 \%$ enterococos vancomicina resistentes (EVR) con valores mínimo de $38.4 \%$ y un máximo de $71.7 \%$. Los EVR fueron identificados como Enterococcus durans. Los enterococos son resistentes a bajo niveles de vancomicina (8mg/L) pero con alta y constante prevalencia. Son también resistentes a tetraciclina (16 mg/L) y a ciprofloxacina $(32 \mathrm{mg} / \mathrm{L})$.

\section{DISCUSIÓN}

Las aguas grises reciben bacterias previamente expuestas a antibióticos provenientes de tratamientos ambulatorios (contaminación fecal) y las presentes en alimentos frescos. En la actividad agrícola ganadera los antibióticos son usados para tratamiento, profilaxis y promoción del crecimiento.

Estudios reportados por Manaia et al. (2010) realizados en plantas de tratamiento de residuos líquidos municipales detectaron mayor prevalencia de bacterias resistentes a ciprofloxacina (1.7-4.4\%) que la encontrada en este trabajo.

Se observó una mayor prevalencia de bacterias resistentes a tetraciclina que en los líquidos residuales hospitalarios (Nuñez, 2010). Si bien algunos estudios como el de CheeSanford et al. (2001) demostraron que la resistencia a tetraciclina en el ambiente proviene principalmente de la actividad agrícola ganadera escasa es la información acerca de la situación en zonas urbanas densamente pobladas de nuestra región. Los datos de prevalencia de resistencia de bacilos Gram negativos resistentes a betalactámicos fueron similares a la detectada en el sistema cloacal de la ciudad de Buenos Aires. 
NUÑEZ, L; TORNELlO, C.; PUENTES, N.; MORETTON, J. Bacterias resistentes a antibióticos en aguas grises como agentes de riesgo sanitario. Ambi-Agua, Taubaté, v. 7, n. 1, p. 235-243, 2012. (http://dx.doi.org/10.4136/ambi-agua.638)

Los estafilococos coagulasa negativos ( $\mathrm{SCN}$ ) meticilina resistentes predominaron entre los aislamientos analizados. En cambio, Faria et al. (2009) en líquidos residuales urbanos, en Portugal, detectó una alta prevalencia de SCN resistentes a eritromicina y no observó la presencia de meticilina resistentes.

Un estudio en Florida también detectó enterococos resistentes a bajas concentraciones de vancomicina $(5 \mathrm{mg} / \mathrm{L})$ en líquidos residuales domiciliarios. En cambio, en líquidos residuales hospitalarios, diferentes autores observaron la presencia de EVR con resistencia a concentraciones notablemente más altas (480 mg/ L) (Harwood et al., 2001; Nuñez, 2010).

Los coliformes presentaron una mayor prevalencia de resistencia a antibióticos $\beta$ lactámicos que las bacterias no fermentadoras de lactosa. Esto resultados sugieren que las bacterias resistentes provienen de la contaminación fecal de las aguas grises.

\section{CONCLUSIONES}

En las aguas grises, la presencia de bacterias no patógenas resistentes representa un riesgo para los seres humanos y el medio ambiente en que pueden actuar como reservorios de resistencia, contribuir al almacenamiento y difusión de los genes de resistencia a los antibióticos.

Los resultados de este trabajo sugieren que las aguas grises pueden contribuir a la diseminación de bacterias resistentes a los antibióticos. Las aguas grises al contener bacterias multirresistentes presentan un riesgo potencial para la salud pública.

Si bien la eliminación de aguas negras o grises por sistemas de canales a cielo abierto es una práctica poco adecuada desde lo sanitario, la situación socio económica que se presenta tanto en asentamientos precarios como en zonas urbanizadas de América Latina indica que continuará siendo una práctica prevalente durante los próximos años.

A pesar de esta situación poco es lo que se ha estudiado acerca del riesgo sanitario que implica esta práctica y menos aún acerca de la resistencia a antibióticos. El presente trabajo es un aporte para un plan de investigación más amplio relacionado con el riesgo sanitario poblacional que realiza este grupo.

\section{REFERENCIAS}

BIRKS R, HILLS S. Characterization of indicator organisms and pathogens in domestic greywater for recycling. Environmental Monitoring Assessment, v.129, p.61-69, 2007. http://dx.doi.org/10.1007/s10661-006-9427-y

CLINICAL AND LABORATORY STANDARDS INSTITUTE (CLSI). Performance standards for antimicrobial susceptibility testing. 18th edn. Approved standard M100-S18. Wayne, 2008.

CASANOVA, L.; LITTLE, V.; FRYE, R.J.; GERBA, C.P. A survey of the microbial quality of recycled household graywater. Journal of the American Water Resources Association, v. 37, p. 1313-1319, 2001. http://dx.doi.org/10.1111/j.1752-1688.2001.tb03641.x

COSTANZO, S.D.; MURBY, J.; BATES, J. Ecosystem response to antibiotics entering the aquatic environmental. Marine Pollution Bulletin, v. 51, p. 218-223, 2005.

http://dx.doi.org/10.1016/j.marpolbul.2004.10.038 
NUÑEZ, L; TORNELlO, C.; PUENTES, N.; MORETTON, J. Bacterias resistentes a antibióticos en aguas grises como agentes de riesgo sanitario. Ambi-Agua, Taubaté, v. 7, n. 1, p. 235-243, 2012. (http://dx.doi.org/10.4136/ambi-agua.638)

CHEE-SANFORD, J. C.; AMINOV, R. I.; KRAPAC, I. J.; GARRIGUES-JEANJEAN, N.; MACKIE, R. I. Occurrence and diversity of tetracycline resistance genes in lagoon and groundwater underlying two swine production facilities. Applied and Environmental Microbiology, v. 67, p. 1494-1502, 2001. http://dx.doi.org/10.1128/AEM.67.4.1494-1502.2001

FARIA, C.; VAZ-MOREIRA, I.; SERAPICOS, E.; NUNES, O. C.; MANAIA, C. M. Antibiotic resistance in coagulase negative staphylococci isolated from wastewater and drinking water. Science of the Total Environment, v.407, p. 3876-3882, 2009. http://dx.doi.org/10.1016/j.scitotenv.2009.02.034

GALLERT, C.; FUND, K. L.; WINTER, J. Antibiotic resistance of bacteria in raw and biologically treated sewage and in groundwater below leaking sewers. Applied Microbiology and Biotechnology, v. 69, p. 106-112, 2005. http://dx.doi.org/10.1007/s00253-005-0033-7

GILBOA, Y.; FRIEDLER, E. UV disinfection of RBC- treated light light greywater effluent: Kinetics, survival and regrowth of select microorganisms. Water research, v. 42, p. 1043-1050, 2008. http://dx.doi.org/10.1016/j.watres.2007.09.027

GUILlAUME, G., VERBRUGGE, D., CHASSEUR-LIBOTTE, M., MOENS, W. AND COLLARD, J. PCR typing of tetracycline resistance determinants (Tet A-E) in Salmonella enterica serotype Hadar and in the microbial community of activated sludges from hospital and urban wastewater treatment facilities in Belgium. FEMS Microbiology Ecology, v.32, p. 77-85, 2000.

GÓMEZ LÓPEZ, M.; ARAUJO PRADO, M.; DÍAZ DÍAZ, M. T.; GARRIDO VÁZQUEZ, J.; SUEIRO, R.; SUÁREZ, S. El tratamiento secundario de aguas residuales comomecanismo redistribuidor de genes de resistencia en bacterias: análisis y evaluación de riesgo. Higiene y Sanidad Ambiental, v. 7, p. 238-250, 2007.

GROSS, A.; KAPLAN, D.; BAKER, B. Removal of chemical and microbiological contaminants from domestic greywater using a recycled vertical flor biorreactor (RVFB). Ecological engineering, v. 31, p. 107-114, 2007.

http://dx.doi.org/10.1016/j.ecoleng.2007.06.006

HARWOOD, V. J.; BROWNELL, M.; PERUSEK, W.; WHITLOCK, J. E. Vancomycinresistant Enterococcus spp. isolated from wastewater and chicken feces in the United States. Applied Environmental Microbiology, v. 67, p. 4930-4933, 2001.

http://dx.doi.org/10.1128/AEM.67.10.4930-4933.2001

HEUER, H.; KROGERRECKLENFORT, E.; WELLINGTON, E. M. H.; EGAN, S.; VAN ELSAS, J. D.; VAN OVERBEEK, L. et al. Gentamicin resistance genes in environmental bacteria: prevalence and transfer. FEMS Microbiology Ecology, v. 42, p. 289-302, 2002. http://dx.doi.org/10.1111/j.1574-6941.2002.tb01019.x

MANAIA, C. M.; NOVO, A.; COELHO, B.; NUNES, O.C. Ciprofloxacin Resistance in Domestic Wastewater Treatment Plants. Water Air Soil Pollution, v. 208, p 335-343, 2010. http://dx.doi.org/10.1007/s11270-009-0171-0

NUÑEZ, L. Riesgo sanitario asociado a líquidos residuales hospitalarios. Disertación (Máster en Investigación y avances en Medicina Preventiva y Salud Pública)Universidad de Granada, Granada, 2010. 
NUÑEZ, L; TORNELlO, C.; PUENTES, N.; MORETTON, J. Bacterias resistentes a antibióticos en aguas grises como agentes de riesgo sanitario. Ambi-Agua, Taubaté, v. 7, n. 1, p. 235-243, 2012. (http://dx.doi.org/10.4136/ambi-agua.638)

NUÑEZ, L.; PAZ, M.; TORNELlO, C.; MANTOVANO, J.;MOLINARI, C.; MORETTON, J. Caracterización microbiológica de aguas grises bajo distintas condiciones de disposición final en Ingeniero Budge (Buenos Aires, Argentina). Higiene y Sanidad Ambiental, v. 10, p. 569$574,2010$.

PATERSON, D. L. Resistance in gram-negative bacteria: Enterobacteriaceae. American Journal of Medicine, v. 119, p. S20-S28, 2006.

http://dx.doi.org/10.1016/j.amjmed.2006.03.013

REINTHALER F.F.,. POSCH J., FEIERL G., WUST G., HAAS D., RUCKENBAUER G., MASCHER F., MARTH E. Antibiotic resistance of E. coli in sewage and sludge. Water Research, v. 37, p.1685-1690, 2003. http://dx.doi.org/10.1016/S0043-1354(02)00569-9

SCHWARTZ, T.; KOHNEN, W.; JANSEN, B.; OBST, U. Detection of antibiotic-resistant bacteria and their resistance genes in wastewater, surface water, and drinking water biofilms. FEMS Microbiology Ecology, v. 43, p. 325-335, 2003. http://dx.doi.org/10.1111/j.1574-6941.2003.tb01073.x

TENNSTEDT, T.; SZCZEPANOWSKI, R.; BRAUN, S.; PUHLER, A.; SCHLUTER, A. Occurrence of integron-associated resistance gene cassetes located on antibiotic resistance plasmids isolated from a wastewater treatment plant. FEMS Microbiology Ecology, v. 45, p. 239-252, 2003. http://dx.doi.org/10.1016/S0168-6496(03)00164-8 